\title{
Commentary: Outliers-Salvage operations and the Society of Thoracic Surgeons risk model
}

\author{
Clark R. Murray, MD, MSc, ${ }^{a}$ and Leora B. Balsam, $\mathrm{MD}^{\mathrm{b}}$
}

\author{
From the ${ }^{\mathrm{a} D e p a r t m e n t}$ of Surgery and ${ }^{\mathrm{b}}$ Division of Cardiac Surgery, UMass Memorial Medical Center, Worcester, \\ Mass. \\ Disclosures: Authors have nothing to disclose with regard to commercial support. \\ Received for publication Feb 10, 2019; accepted for publication Feb 11, 2019; available ahead of print March 26, \\ 2019. \\ Address for reprints: Leora B. Balsam, MD, Division of Cardiac Surgery UMass Memorial Medical Center, Uni- \\ versity Campus 55 Lake Ave N, Worcester, MA 01655 (E-mail: leora.balsam@umassmemorial.org). \\ J Thorac Cardiovasc Surg 2020;159:203-4 \\ $0022-5223 / \$ 36.00$ \\ Copyright (c) 2019 by The American Association for Thoracic Surgery \\ https://doi.org/10.1016/j.jtcvs.2019.02.049
}

The cardiac surgeon is often faced with difficult decisions that may alter the course of a patient's life. This is no more evident than in salvage operations, defined in the Society of Thoracic Surgeons (STS) National Database as cases in which patients are actively receiving cardiopulmonary resuscitation or require extracorporeal membrane oxygenation for stabilization immediately before surgery. Whether to offer surgery under these conditions is a decision that must be made, considering both clinical factors and the wishes of the patient. Establishing consensus among the clinical team is necessary, and for cases that are deemed futile, surgery should not be offered.

In this issue of the Journal, Chancellor and colleagues ${ }^{1}$ hypothesize that risk aversion arising from public reporting of outcomes in cardiac surgery affects decision making in salvage cases. By applying the STS model for predicted risk of operative mortality, they compare observed to expected operative mortality in elective, urgent, emergency, and salvage cases from a regional database of 19 cardiac surgery centers in Virginia and North Carolina (Virginia Cardiac Services Quality Initiative) during a period from 2002 to 2017. Primary coronary artery bypass grafting, isolated valve operations, and combined coronary artery bypass grafting and valve cases were analyzed. Among the 76,498 cases, only 117 were salvage cases $(0.15 \%)$. Chancellor and colleagues ${ }^{1}$ find better concordance between the observed and predicted mortalities in lower and moderate risk cases, with worse agreement in the salvage cases. The predicted risk of mortality was higher than the observed risk in the salvage cases, with a mean observed to expected ratio of 1.41 (95\% confidence interval, $1.06-$ 1.84).

When assessing the fit of the STS model to the salvage cases, one must consider several factors. First, disagreement with the model in this small subset does not imply that the model works badly. The model is designed to fit the larger STS cohort, and as Chancellor and colleagues ${ }^{1}$ demonstrate, it does this quite well. Second, with regard to salvage

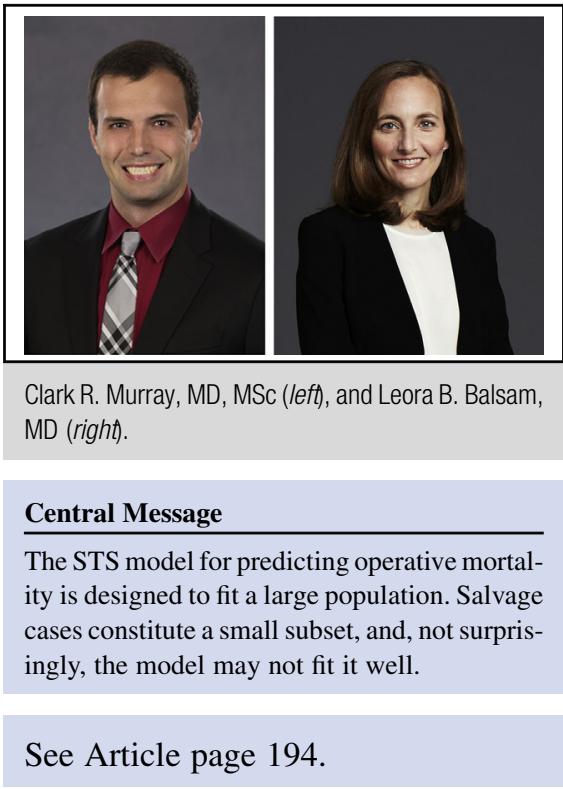

cases, there are missing data elements that may affect the model's fit with this subset. These include all the cases declined by surgeons because of perceived futility. It may in fact be that were these included in the calculation, the predicted and observed risk of mortality would align more closely.

Chancellor and colleagues ${ }^{1}$ suggest that risk aversion arising from public reporting may play a role in surgical decision making in salvage cases. This particular hypothesis is difficult to prove, and public reporting notably is voluntary in the states that participate in the Virginia Cardiac Services Quality Initiative (Virginia and North Carolina). Risk aversion arising from public reporting has not been easy to demonstrate in cardiac surgery, and a recent report from Shahian and colleagues ${ }^{2}$ found little evidence that it influences decision making in cardiac surgery. Most studies that have explored this topic have looked for shifts in patient acuity and risk, typically from geographic regions that have cardiac surgery public reporting to those that do not, spanning a period before and after public reporting. In general, these studies have not been able to find evidence that risk aversion occurs as a result of public reporting of cardiac surgery outcomes. This is unlike the field of interventional cardiology, in which risk aversion has been more easily identified in the context of percutaneous coronary intervention for acute myocardial infarction with cardiogenic shock. $^{2,3}$ 
One of the more important findings of this study was that inclusion of salvage cases did not noticeably affect the centers' overall mortalities. Because these were rare cases, the overall mortalities were driven by the more frequent elective, urgent, and emergency cases. This point is emphasized in Table E1 from that article.

Chancellor and colleagues ${ }^{1}$ draw attention to a vulnerable patient population that may have the most to gain from intervention. The conclusions to draw from the study are that (1) the STS model should not be expected to fit this small subset, (2) this study neither proves nor disproves the hypothesis that risk aversion arising from public reporting exists in cardiac surgery, and (3) outcomes of rare salvage cases do not appreciably influence a center's overall observed to expected mortality ratio when applying the STS model.

\section{References}

1. Chancellor WZ, Mehaffey JH, Beller JP, Krebs ED, Hawkins RB, Yount K, et al. Current quality reporting methods are not adequate for salvage cardiac operations. J Thorac Cardiovasc Surg. 2020;159:194-200.e1.

2. Shahian DM, Jacobs JP, Badhwar V, D’Agostino RS, Bavaria JE, Prager RL. Risk aversion and public reporting. Part 1: observations from cardiac surgery and interventional cardiology. Ann Thorac Surg. 2017;104:2093-101.

3. McCabe JM, Waldo SW, Kennedy KF, Yeh RW. Treatment and outcomes of acute myocardial infarction complicated by shock after public reporting policy changes in New York. JAMA Cardiol. 2016;1:648-54. 